\title{
Neonatal Seizure Models to Study Epileptogenesis
}

\author{
Yuka Kasahara, Yuji Ikegaya and Ryuta Koyama* \\ Laboratory of Chemical Pharmacology, Graduate School of Pharmaceutical Sciences, The University of Tokyo, Tokyo, Japan
}

\section{OPEN ACCESS}

Edited by:

Annamaria Vezzani, Istituto di Ricerche Farmacologiche Mario Negri, Italy

Reviewed by: Nasiara Karim University of Malakand, Pakistan Yoshitoshi Kasuya, Chiba University, Japan

*Correspondence: Ryuta Koyama rkoyama@mol.f.u-tokyo.ac.jp

Specialty section: This article was submitted to

Neuropharmacology, a section of the journal Frontiers in Pharmacology

Received: 17 January 2018 Accepted: 04 April 2018 Published: 18 April 2018

Citation:

Kasahara Y, Ikegaya $Y$ and Koyama R (2018) Neonatal Seizure Models to Study Epileptogenesis. Front. Pharmacol. 9:385. doi: 10.3389/fphar.2018.00385
Current therapeutic strategies for epilepsy include anti-epileptic drugs and surgical treatments that are mainly focused on the suppression of existing seizures rather than the occurrence of the first spontaneous seizure. These symptomatic treatments help a certain proportion of patients, but these strategies are not intended to clarify the cellular and molecular mechanisms underlying the primary process of epilepsy development, i.e., epileptogenesis. Epileptogenic changes include reorganization of neural and glial circuits, resulting in the formation of an epileptogenic focus. To achieve the goal of developing "anti-epileptogenic" drugs, we need to clarify the step-by-step mechanisms underlying epileptogenesis for patients whose seizures are not controllable with existing "anti-epileptic" drugs. Epileptogenesis has been studied using animal models of neonatal seizures because such models are useful for studying the latent period before the occurrence of spontaneous seizures and the lowering of the seizure threshold. Further, neonatal seizure models are generally easy to handle and can be applied for in vitro studies because cells in the neonatal brain are suitable for culture. Here, we review two animal models of neonatal seizures for studying epileptogenesis and discuss their features, specifically focusing on hypoxia-ischemia (HI)-induced seizures and febrile seizures (FSs). Studying these models will contribute to identifying the potential therapeutic targets and biomarkers of epileptogenesis.

Keywords: neonatal seizures, epilepsy, hypoxia-ischemia, febrile seizures, bumetanide

\section{INTRODUCTION}

The neonatal period is at higher risk of having seizures than other periods in life (Annegers et al., 1995). A population study indicated the incidence of seizures to be 1-5 per 1000 live births (Saliba, 2001; Volpe, 2008; Glass, 2014). Early life insults such as hypoxic-ischemic encephalopathy and fever are major causes of neonatal seizures (Rakhade and Jensen, 2009), and it has been reported that $16-56 \%$ of neonates that experience seizures develop epilepsy later in life (Mizrahi and Watanabe, 2005; Pisani et al., 2012). The primary process whereby principal neurons generate the first spontaneous and epileptiform discharges is referred to as epileptogenesis and is often accompanied by both structural and functional alteration of neuronal circuits (Goldberg and Coulter, 2013). Classical anticonvulsants, i.e., anti-epileptic drugs, are used to suppress ongoing and future seizures but not to prevent the onset of epilepsy (Temkin, 2009). Therapeutic strategies targeting the prevention of epileptogenesis are expected to prevent the onset of epilepsy, i.e., the occurrence of the first spontaneous epileptic seizures. To develop such "anti-epileptogenic" treatments, the cellular and molecular mechanisms underlying epileptogenesis have been studied using animal models of neonatal seizures (Dubé et al., 2006, 2010; Kadam et al., 2010). This minireview will provide an overview of the representative animal models of neonatal seizures, especially 
focusing on rodent models of hypoxia-ischemia (HI)-induced seizures and febrile seizures (FSs) (Dubé et al., 2010; Sun et al., 2016). We will also discuss potential pharmacological strategies that could target epileptogenic changes observed in neonatal seizure models.

\section{HYPOXIA-ISCHEMIA (HI) MODELS}

Neonatal seizures are often induced by perinatal asphyxia with a critical lack of oxygen during labor and delivery (Sun et al., 2016). To study this type of seizure and its sequelae, experimental HI-induced seizures have been extensively used. In this section, we will introduce rodent models of $\mathrm{HI}$ that are potentially useful to identify mechanisms that mediate epileptogenesis in the immature brain. Rice et al. (1981) first established a rat neonatal HI model known as the Rice-Vannucci model. The Rice-Vannucci model and its derivatives have been widely used to study neonatal HI. For preparing the HI model, rat pups of both sexes are typically used at postnatal day 7 (P7)-P10 because the brain development during this period roughly corresponds to that of humans in late embryonic to early postnatal periods (Talos et al., 2006; Rakhade and Jensen, 2009). It should be noted that sex differences in susceptibility to HI have been reported (Smith et al., 2014a). To induce HI, rat pups are exposed to a hypoxic environment $\left(8 \% \mathrm{O}_{2}\right.$ in $\left.\mathrm{N}_{2}\right)$ for 30 min- $2.5 \mathrm{~h}$ (sometimes up to $4 \mathrm{~h}$ ) after ligation of the lateral common carotid artery. In this system, brain damage, including selective neuronal necrosis and infarction in the ipsilateral cerebral cortex, striatum, and hippocampus, was observed in no less than $90 \%$ of HI-induced animals and within $50 \mathrm{~h}$ after $\mathrm{HI}$ induction (Rice et al., 1981). In addition, the authors revealed that lower $\mathrm{O}_{2}$ levels and longer exposure time to $\mathrm{HI}$ resulted in more-severe brain damage (Rice et al., 1981; Cuaycong et al., 2011). In HI models, cortical damage is mainly observed in columns at right angles to the pial surface, a pattern that is also observed in human infants who experienced repeated hypoxia-acidosis with hypotension (Norman, 1981; Rice et al., 1981). HI models also replicate many histological features, such as porencephalic cysts and cortical microgyri, observed in brains of infants with hypoxic-ischemic encephalopathy (Williams et al., 2004; Kadam and Dudek, 2007; Williams and Dudek, 2007). Further, 90 min of HI treatment evoked cortical electrographic seizures with correlated behavioral movements in 92\% (11 of 12) and electrographic seizures in 83\% (10 of 12) of the rats (Cuaycong et al., 2011). Additionally, simultaneous video monitoring and electroencephalogram (EEG) recording during and after $\mathrm{HI}$ induction revealed that all rats (12 of 12) showed electroclinical seizures, defined as EEG patterns abnormal in amplitude and frequency, and that the seizures persist for $24 \mathrm{~h}$ in 67\% ( 8 of 12) and $48 \mathrm{~h}$ in 25\% (3 of 12) (Sampath et al., 2014).

\section{SEIZURE PHENOTYPES FOLLOWING HI INDUCTION}

Kadam et al. (2010) examined whether HI insults initiate epileptogenic processes. Rat pups at P7 underwent unilateral carotid ligation followed by a hypoxic environment $\left(8 \% \mathrm{O}_{2}\right.$, $2 \mathrm{~h}$ ), and continuous radio-telemetry and video recording of cortical electroencephalographic and behavioral seizures were performed from 2 to 12 months of age. It was reported that $56 \%$ (10 of 18) of HI-induced rats develop spontaneous epileptiform discharges and recurrent seizures. Furthermore, all rats with spontaneous electrographic seizures exhibited obvious cystic infarcts in the ipsilateral hemisphere, although the seizure rate per day did not always depend on the severity of infarct. Rats without spontaneous seizures exhibited no infarct and no associated neuronal death. It was suggested that the occurrence of cortical abnormalities is associated with the acquisition of epileptogenesis, i.e., the occurrence of first spontaneous seizures. Spontaneous electrographic seizures, which are often accompanied by behavioral seizures, occurred in distinct clusters with seizure-free periods as long as a few weeks and progressively became more severe and more frequent over time. In addition, 24-h behavioral monitoring for a week/month in HI-induced rats starting from P30 revealed that behavioral seizures were not detected until the second month of monitoring (Kadam and Dudek, 2007). These results indicate that the process of epileptogenesis requires a long and continuous latency period, which may allow therapeutic intervention to prevent subsequent progression of the epileptogenic process, especially by suppressing structural brain damage.

Some studies, however, reported few or no incidence of spontaneous seizures following HI (Table 1). When mouse pups were subjected to $\mathrm{HI}$ induction at P7 with a ligation of the lateral common carotid artery and a subsequent hypoxic challenge ( $8 \% \mathrm{O}_{2}$ for $45 \mathrm{~min}$ ), evident epileptiform discharges were not observed at 2-3 months of age during hippocampal and cortical EEG recordings performed 5-8 h/day for 3-4 days (Peng et al., 2015). Chronic video monitoring for 10 consecutive days revealed that motor seizures occurred in only 2 of 23 post-HI mice. In addition, to evaluate seizure susceptibility of HI-induced mice, the authors stimulated the hippocampus with square current pulses to evoke motor seizures and found no evidence of increased seizure susceptibility in HI mice. These conflicting data in terms of reproducing HI-induced development of epilepsy may be attributable to the differences in animal species, sex (both sexes are often mixed), hypoxic environment (especially the duration of hypoxia), seizure criteria, and EEG recording time, as well as to the small numbers of animals in control groups in some cases. The establishment of stable HI models using mice is awaited because transgenic lines are more available in mice than in rats and will enable the study of cellular and molecular mechanisms underlying epileptogenesis.

\section{FEBRILE SEIZURE (FS) MODELS}

Fever (typically greater than $38^{\circ} \mathrm{C}$ )-induced FSs are the most common childhood seizures, with a prevalence of 2-14\% worldwide (Verity and Golding, 1991; Vestergaard and Christensen, 2009; Koyama and Matsuki, 2010). FSs usually 
TABLE 1 | Epileptogenesis in neonatal seizure models.

\begin{tabular}{|c|c|c|c|c|c|c|}
\hline Model & $\begin{array}{l}\text { Animal } \\
\text { species/strain }\end{array}$ & Age & $\begin{array}{l}\text { Behavioral seizures } \\
\text { during induction }\end{array}$ & $\begin{array}{l}\text { Electrographic } \\
\text { seizures during } \\
\text { induction }\end{array}$ & $\begin{array}{l}\text { Spontaneous } \\
\text { seizures }\end{array}$ & Reference \\
\hline $\mathrm{HI}$ & $\begin{array}{l}\text { Sprague- } \\
\text { Dawley rats }\end{array}$ & P30 & $\mathrm{N} / \mathrm{A}$ & $\mathrm{N} / \mathrm{A}$ & $15 \%$ (3 of 20$)$ & Williams and Dudek, 2007 \\
\hline $\mathrm{HI}$ & $\begin{array}{l}\text { Sprague-- } \\
\text { Dawley rats }\end{array}$ & $\mathrm{P} 7$ & $\mathrm{~N} / \mathrm{A}$ & $\mathrm{N} / \mathrm{A}$ & $30 \%$ (3 Of 10$)$ & Kadam and Dudek, 2007 \\
\hline $\mathrm{HI}$ & $\begin{array}{l}\text { Sprague-- } \\
\text { Dawley rats }\end{array}$ & $\mathrm{P} 7$ & $\mathrm{~N} / \mathrm{A}$ & N/A & $56 \%(10$ of 18$)$ & Kadam et al., 2010 \\
\hline Hypoxia & Long-Evans rats & P10 & $93 \%$ (58 of 61$)$ & Yes & $94 \%(48$ of 51$)$ & Rakhade et al., 2011 \\
\hline FS & $\begin{array}{l}\text { Sprague-- } \\
\text { Dawley rats }\end{array}$ & P10-11 & Yes & $\mathrm{N} / \mathrm{A}$ & $35 \%(6$ of 17$)$ & Dubé et al., 2006 \\
\hline FS & $\begin{array}{l}\text { Sprague-- } \\
\text { Dawley rats }\end{array}$ & P11 & Yes & N/A & $50 \%$ (8 of 16$)$ & Koyama et al., 2012 \\
\hline Kainic acid & c-Dawley rats & P5-60 & Yes & Yes & $\begin{array}{c}\text { N/A (KA at P5, P10) } \\
14 \% \text { (P20) 30\% (P30) } \\
44 \%(P 60)\end{array}$ & Stafstrom et al., 1992 \\
\hline Flurothyl & $\begin{array}{l}\text { Sprague-- } \\
\text { Dawley rats }\end{array}$ & PO-9 & Yes & $\mathrm{N} / \mathrm{A}$ & $\begin{array}{l}\text { Increased seizure } \\
\text { susceptibility to flurothyl }\end{array}$ & Huang et al., 1999 \\
\hline
\end{tabular}

HI, hypoxia-ischemia; FS, febrile seizure.

occur between 3 months and 5 years of age with the peak at 16-18 months. Although simple FSs are mostly benign, complex FSs with prolonged duration ( $>15 \mathrm{~min}$ ), recurrent seizures or focal neurological features are associated with the development of temporal lobe epilepsy (Cendes et al., 1993; French et al., 1993; Theodore et al., 1999). To investigate the potential consequences of complex FSs and to screen potential anti-epileptogenic drugs, various highly reproducible animal models have been developed (Koyama, 2017). In these models, prolonged seizures are induced by exposing rodent pups to a hyperthermic environment to simulate fever-like conditions; the main such models are the hair dryer model (Dubé et al., 2000; Koyama et al., 2012; Tao et al., 2016), heated chamber model (Holtzman et al., 1981; Schuchmann et al., 2006), hot water model (Ullal et al., 1996; Jiang et al., 1999), microwave model (Hjeresen et al., 1983), and lipopolysaccharide model (Heida et al., 2004). Although there are limitations to completely mimicking clinical phenotypes of FSs in human neonates, experimental hyperthermia can induce the release of fever mediators that are necessary for the onset of FSs (Dubé et al., 2005).

Baram and his colleagues developed and refined the hair dryer model that is widely used (Toth et al., 1998; Dubé et al., 2010). In this model, P10-11 Sprague-Dawley rats or P14-15 129/Sv or C57BL/6 mice are often used because the developmental stage of hippocampus is roughly comparable to that in human infants, which are most susceptible to FSs. Significant sex differences were not observed, at least for the seizure duration (Lemmens et al., 2005). It has been reported that differences in mouse strain affect susceptibility to FS induction (van Gassen et al., 2008). Prolonged FSs are generated by maintaining hyperthermia (typically $38.5-42.5^{\circ} \mathrm{C}$ ) for $30 \mathrm{~min}$. During hyperthermia, the rectal temperature is measured every $2 \mathrm{~min}$ to maintain core temperature between 38.5 and $42.5^{\circ} \mathrm{C}$, which corresponds to the threshold temperature to evoke complex FSs in human neonates.
Hyperthermic controls can be conducted by administering barbiturates to suppress seizures for distinguishing whether the observed FS consequences result from the seizures or the hyperthermia. The onset of experimental FSs typically consists of an acute sudden arrest of hyperthermia-induced hyperactivity, such as oral automatism and running. Oral automatism is typically followed by forelimb clonus. In the later phase of FSs, tonic body flexion is often observed in rats, but it is rare in mice.

\section{SEIZURE PHENOTYPES FOLLOWING FS INDUCTION}

Dubé et al. (2000) showed that FSs during development decreased the seizure threshold in later life in rats. In brief, all the rats (11 of 11) at 10-11 weeks following early life FSs developed hippocampal seizures, and most (8 of 11) experienced status epilepticus after intraperitoneal administration of a subthreshold dose of the chemical convulsant kainate $(5 \mathrm{mg} / \mathrm{kg})$. In contrast, most normothermic (6 of 8) and hyperthermic controls without seizures (5 of 6) did not exhibit seizures or kainite-induced status epilepticus. The authors prepared hippocampal-entorhinal cortical slices 1 week after FS induction and then stimulated Schaeffer collaterals, observing more prolonged status epilepticus-like discharges than in control slices. The same research group examined whether experimental FSs induce spontaneous seizures by performing chronic monitoring of behaviors and EEGs from the hippocampus and cortex (Dubé et al., 2006). 2 months after FS induction, bipolar electrodes were implanted unilaterally into the dorsal hippocampus and frontoparietal cortex. After the surgery, long-term video-EEG recordings were performed on postnatal days 90,105,120,135, 165, and 180 for $5 \mathrm{~h}$ at night. None of the normothermic or hyperthermic 
controls developed spontaneous seizures or interictal events, whereas behavioral and hippocampal electrographic spontaneous seizures in 35\% (6 of 17) and interictal epileptiform EEG abnormalities in $88 \%$ (15 of 17) of FS rats were observed. Moreover, longer duration of experimental FSs increased the probability of developing subsequent spontaneous seizures (Dubé et al., 2010). These results suggest that hyperthermiainduced experimental FSs lead to progression of the epileptogenic process.

\section{PHARMACOLOGICAL STRATEGIES}

Neonatal seizures should be treated adequately and rapidly because prolonged seizures would result in severe neurological morbidity (Ronen et al., 2007; Jensen, 2009). However, seizures in neonatal periods are sometimes resistant to conventional anti-epileptic drugs. For example, phenobarbital, which binds to an allosteric site on the $\mathrm{GABA}_{\mathrm{A}}$ receptor and thereby potentiates the action of endogenous GABA, has been used as the first-line treatment for neonatal seizures (WHO) (World Health Organization, 2011). However, studies have reported that fewer than $50 \%$ of neonates with seizures respond to phenobarbital in terms of the suppression of electrographic seizures (Painter et al., 1999; Boylan et al., 2002, Rennie and Boylan, 2007). In addition, it has been reported that phenobarbital could induce the apoptosis of neurons in gray and white matter and impair synaptic connectivity in the immature brain (Bittigau et al., 2003; Forcelli et al., 2012; Kaushal et al., 2016). Moreover, the administration of phenobarbital is associated with long-term alterations in behavioral phenotypes, including impaired cognition and depressive behaviors (Stefovska et al., 2008; Brodie and Kwan, 2012). Thus, more efficient pharmacological treatment than the use of phenobarbital alone should be considered to enhance the inhibitory effects of GABA in neonatal periods.

Because GABA can depolarize immature neurons that overwhelm mature neurons in the developing brain, GABAmimetic and GABA-modulating anti-epileptic drugs are relatively ineffective in neonatal seizures. It depends on the intracellular $\mathrm{Cl}^{-}$levels and the $\mathrm{Cl}^{-}$equilibrium potential whether GABA provokes inhibitory or excitatory actions. The intracellular $\mathrm{Cl}^{-}$levels are mainly controlled by cationchloride cotransporter (CCC) family that involves $\mathrm{Na}^{+} \mathrm{K}^{+} 2 \mathrm{Cl}^{-}$ co-transporter isoform 1 (NKCC1), which mediates $\mathrm{Cl}^{-}$ influx, and $\mathrm{K}^{+} 2 \mathrm{Cl}^{-}$cotransporter isoform 2 (KCC2), which mediates $\mathrm{Cl}^{-}$efflux. The balance in the expression levels of NKCC1 and KCC2 shapes the developmental changes in the actions of GABA: early expression of NKCC1 and late expression of KCC2 underlie the excitatory action of GABA in immature neurons because of an elevated intracellular $\mathrm{Cl}^{-}$ level and a depolarized $\mathrm{Cl}^{-}$equilibrium potential. It has been suggested that the diuretic bumetanide, a selective NKCC1 inhibitor, could be useful for epileptogenic treatment (Löscher et al., 2013a,b), although it should be noted that the efficacy of bumetanide is still controversial (Puskarjov et al., 2014;
Ben-Ari et al., 2016; Hernan and Holmes, 2016). It has been reported that bumetanide blocked kainate-induced seizures in neonatal rats (Dzhala et al., 2005) and that the treatment of bumetanide alone or bumetanide with phenobarbital decreased seizure events and susceptibility after early life seizures in some animal models (Cleary et al., 2013; Holmes et al., 2015; Hu et al., 2017). Koyama et al. (2012) revealed that excitatory $\mathrm{GABA}_{\mathrm{A}}$ signaling mediates the emergence of ectopic granule cells that lead to hippocampal hyperexcitability and the development of epilepsy in FS rats. Continuous administration of bumetanide $(0.1 \mathrm{mg} / \mathrm{kg}$, i.p. $)$ after FSs attenuated ectopic localization of granule cells, susceptibility to limbic seizures and development of epilepsy. In an $\mathrm{HI}$ model, bumetanide suppressed mossy fiber sprouting, an anatomical hallmark that may shape epileptogenic neural circuits (Koyama and Ikegaya, 2004), after hypoxia and prevented the onset of spontaneous electrographic seizures (Wang et al., 2015). In human patients, Pressler et al. (2015) conducted a trial of bumetanide for infants with hypoxicischemic encephalopathy, but this study was terminated due to the lack of clear efficacy and side effects of bumetanide. In clinical trials of human neonatal seizures, subjects are limited to infants with phenobarbital-resistant refractory seizures.

For the development of anti-epileptogenic drugs, future studies using various prodrugs of bumetanide or alternative NKCC1 blockers with enhanced penetration into the brain through the blood brain barrier, or drugs that enhance $\mathrm{Cl}^{-}$ extrusion via KCC2, are essential (Löscher et al., 2013b; Kaila et al., 2014; Puskarjov et al., 2014). The efficacy of bumetanide would depend on seizure phenotypes and the stage of epileptogenic process. Thus, it is important to clarify the changing roles of GABAergic signaling in the early and late phase of epileptogenesis. Some studies have reported the involvement of excitatory $\mathrm{GABA}_{\mathrm{A}}$ signaling in rather late phase of epileptogenic changes, i.e., structural changes, after neonatal seizures (Koyama et al., 2012; Wang et al., 2015). However, the roles of excitatory $\mathrm{GABA}_{\mathrm{A}}$ signaling in very early stage of epileptogenesis remain unclear. Thus, proper methods for recording the changes in neuronal activity in the onset of neonatal seizures to examine the effects of GABAergic signaling are necessary.

\section{CONCLUSION}

Proper treatment of neonatal seizures is essential to prevent the future development of epilepsy. However, evidence-based guidelines for pharmacological treatment are lacking (Slaughter et al., 2013; Glass, 2014). In this mini-review, we described two representative animal models of neonatal seizures with a relatively higher risk of epilepsy later in life. These animal models successfully replicate some of the structural abnormalities and cognitive dysfunctions that have been reported in human individuals who experienced neonatal seizures (Dubé et al., 2009; Smith et al., 2014b; Tao et al., 2016). However, the findings from the experimental neonatal seizures are not always consistent. 
To avoid the inconsistency, it is of importance to consider the differences in experimental conditions such as animal species, sexes, developmental stages, and the criteria used to categorize seizures. It is also helpful to develop additional experimental models that mimic the initial triggers of neonatal seizures in humans, for example, exanthema subitum or influenza that lead to fever production. It should be also noted that the biomarkers to diagnose the development of epilepsy later in life need to be discovered, especially in terms of drug administration to infants and children. The proper adoption and use of animal models will allow investigators to clarify the cellular and molecular mechanisms of epileptogenesis following neonatal seizures and to identify pharmacological targets and biomarkers in human neonates.

\section{REFERENCES}

Annegers, J. F., Hauser, W. A., Lee, J. R., and Rocca, W. A. (1995). Incidence of acute symptomatic seizures in Rochester, Minnesota, 1935-1984. Epilepsia 36, 327-333. doi: 10.1111/j.1528-1157.1995.tb01005.x

Ben-Ari, Y., Damier, P., and Lemonnier, E. (2016). Failure of the nemo trial: bumetanide is a promising agent to treat many brain disorders but not newborn seizures. Front. Cell. Neurosci. 10:90. doi: 10.3389/fncel.2016.00090

Bittigau, P., Sifringer, M., and Ikonomidou, C. (2003). Antiepileptic drugs and apoptosis in the developing brain. Ann. N. Y. Acad. Sci. 993, 103-114. doi: 10.1111/j.1749-6632.2003.tb07517.x

Boylan, G. B., Rennie, J. M., Pressler, R. M., Wilson, G., Morton, M., and Binnie, C. D. (2002). Phenobarbitone, neonatal seizures, and video-EEG. Arch. Dis. Child. Fetal Neonatal Ed. 86, F165-F170. doi: 10.1136/fn.86.3.F165

Brodie, M. J., and Kwan, P. (2012). Current position of phenobarbital in epilepsy and its future. Epilepsia 53(Suppl. 8), 40-46. doi: 10.1111/epi.12027

Cendes, F., Andermann, F., Dubeau, F., Gloor, P., Evans, A., Jones-Gotman, M., et al. (1993). Early childhood prolonged febrile convulsions, atrophy and sclerosis of mesial structures, and temporal lobe epilepsy: an MRI volumetric study. Neurology 43, 1083-1087. doi: 10.1212/WNL.43.6.1083

Cleary, R. T., Sun, H., Huynh, T., Manning, S. M., Li, Y., Rotenberg, A., et al. (2013). Bumetanide enhances phenobarbital efficacy in a rat model of hypoxic neonatal seizures. PLoS One 8:e57148. doi: 10.1371/journal.pone.0057148

Cuaycong, M., Engel, M., Weinstein, S. L., Salmon, E., Perlman, J. M., Sunderam, S., et al. (2011). A novel approach to the study of hypoxia-ischemia-induced clinical and subclinical seizures in the neonatal rat. Dev. Neurosci. 33, 241-250. doi: 10.1159/000331646

Dubé, C., Chen, K., Eghbal-Ahmadi, M., Brunson, K., Soltesz, I., and Baram, T. Z. (2000). Prolonged febrile seizures in the immature rat model enhance hippocampal excitability long term. Ann. Neurol. 47, 336-344. doi: 10.1002/ 1531-8249(200003)47:3<336::AID-ANA9>3.0.CO;2-W

Dubé, C., Richichi, C., Bender, R. A., Chung, G., Litt, B., and Baram, T. Z. (2006). Temporal lobe epilepsy after experimental prolonged febrile seizures: prospective analysis. Brain 129, 911-922. doi: 10.1093/brain/ awl018

Dubé, C., Vezzani, A., Behrens, M., Bartfai, T., and Baram, T. Z. (2005). Interleukin- $1 \beta$ contributes to the generation of experimental febrile seizures. Ann. Neurol. 57, 152-155. doi: 10.1002/ana.20358

Dubé, C. M., Ravizza, T., Hamamura, M., Zha, Q., Keebaugh, A., Fok, K., et al. (2010). Epileptogenesis provoked by prolonged experimental febrile seizures: mechanisms and biomarkers. J. Neurosci. 30, 7484-7494. doi: 10.1523/ JNEUROSCI.0551-10.2010

Dubé, C. M., Zhou, J. L., Hamamura, M., Zhao, Q., Ring, A., Abrahams, J., et al. (2009). Cognitive dysfunction after experimental febrile seizures. Exp. Neurol. 215, 167-177. doi: 10.1016/j.expneurol.2008.10.003

Dzhala, V. I., Talos, D. M., Sdrulla, D. A., Brumback, A. C., Mathews, G. C., Benke, T. A., et al. (2005). NKCC1 transporter facilitates seizures in the developing brain. Nat. Med. 11, 1205-1213. doi: 10.1038/nm1301

\section{AUTHOR CONTRIBUTIONS}

YK and RK wrote the manuscript. YK, RK, and YI discussed the manuscript.

\section{FUNDING}

This research was supported in part by a Grant-in-Aid for Scientific Research (B) (17H03988 to RK) from JSPS and by a Grant-in-Aid for Scientific Research on Innovation Area "Glial Assembly" (16H01329 to RK) and "Dynamic Regulation of Brain Function by Scrap \& Build System” (17H05738 to RK) from MEXT and by Nagai Memorial Research Scholarship from the Pharmaceutical Society of Japan.

Forcelli, P. A., Janssen, M. J., Vicini, S., and Gale, K. (2012). Neonatal exposure to antiepileptic drugs disrupts striatal synaptic development. Ann. Neurol. 72, 363-372. doi: 10.1002/ana.23600

French, J. A., Williamson, P. D., Thadani, V. M., Darcey, T. M., Mattson, R. H., Spencer, S. S., et al. (1993). Characteristics of medial temporal lobe epilepsy: I. Results of history and physical examination. Ann. Neurol. 34, 774-780. doi: 10.1002/ana.410340604

Glass, H. C. (2014). Neonatal seizures: advances in mechanisms and management. Clin. Perinatol. 41, 177-190. doi: 10.1016/j.clp.2013. 10.004

Goldberg, E. M., and Coulter, D. A. (2013). Mechanisms of epileptogenesis: a convergence on neural circuit dysfunction. Nat. Rev. Neurosci. 14, 337-349. doi: $10.1038 / \mathrm{nrn} 3482$

Heida, J. G., Boisse, L., and Pittman, Q. J. (2004). Lipopolysaccharide-induced febrile convulsions in the rat: short-term sequelae. Epilepsia 45, 1317-1329. doi: 10.1111/j.0013-9580.2004.13704.x

Hernan, A. E., and Holmes, G. L. (2016). Antiepileptic drug treatment strategies in neonatal epilepsy. Prog. Brain Res. 226, 179-193. doi: 10.1016/bs.pbr.2016. 03.011

Hjeresen, D. L., Guy, A. W., Petracca, F. M., and Diaz, J. (1983). A microwavehyperthermia model of febrile convulsions. Bioelectromagnetics 4, 341-355. doi: 10.1002/bem.2250040406

Holmes, G. L., Tian, C., Hernan, A. E., Flynn, S., Camp, D., and Barry, J. (2015). Alterations in sociability and functional brain connectivity caused by early-life seizures are prevented by bumetanide. Neurobiol. Dis. 77, 204-219. doi: 10.1016/j.nbd.2015.02.015

Holtzman, D., Obana, K., and Olson, J. (1981). Hyperthermia-induced seizures in the rat pup: a model for febrile convulsions in children. Science 213, 1034-1036. doi: 10.1126/science.7268407

Hu, J. J., Yang, X. L., Luo, W. D., Han, S., Yin, J., Liu, W. H., et al. (2017). Bumetanide reduce the seizure susceptibility induced by pentylenetetrazol via inhibition of aberrant hippocampal neurogenesis in neonatal rats after hypoxiaischemia. Brain Res. Bull. 130, 188-199. doi: 10.1016/j.brainresbull.2017. 01.022

Huang, L., Cilio, M. R., Silveira, D. C., McCabe, B. K., Sogawa, Y., Stafstrom, C. E., et al. (1999). Long-term effects of neonatal seizures: a behavioral, electrophysiological, and histological study. Brain Res. Dev. Brain Res. 118, 99-107. doi: 10.1016/S0165-3806(99)00135-2

Jensen, F. E. (2009). Neonatal seizures: an update on mechanisms and management. Clin. Perinatol. 36, 881-900. doi: 10.1016/j.clp.2009.08.001

Jiang, W., Duong, T. M., and de Lanerolle, N. C. (1999). The neuropathology of hyperthermic seizures in the rat. Epilepsia 40, 5-19. doi: 10.1111/j.1528-1157. 1999.tb01982.x

Kadam, S. D., and Dudek, F. E. (2007). Neuropathogical features of a rat model for perinatal hypoxic-ischemic encephalopathy with associated epilepsy. J. Comp. Neurol. 505, 716-737. doi: 10.1002/cne.21533

Kadam, S. D., White, A. M., Staley, K. J., and Dudek, F. E. (2010). Continuous electroencephalographic monitoring with radio-telemetry 
in a rat model of perinatal hypoxia-ischemia reveals progressive poststroke epilepsy. J. Neurosci. 30, 404-415. doi: 10.1523/JNEUROSCI.409309.2010

Kaila, K., Price, T. J., Payne, J. A., Puskarjov, M., and Voipio, J. (2014). Cationchloride cotransporters in neuronal development, plasticity and disease. Nat. Rev. Neurosci. 15, 637-654. doi: 10.1038/nrn3819

Kaushal, S., Tamer, Z., Opoku, F., and Forcelli, P. A. (2016). Anticonvulsant druginduced cell death in the developing white matter of the rodent brain. Epilepsia 57, 727-734. doi: 10.1111/epi.13365

Koyama, R. (2017). "Experimental febrile seizures in rodents," in Animal Models for the Study of Human Disease, 2nd Edn, ed. P. M. Conn (New York, NY: Elsevier Press), 755-768. doi: 10.1016/B978-0-12-809468-6.00029-2

Koyama, R., and Ikegaya, Y. (2004). Mossy fiber sprouting as a potential therapeutic target for epilepsy. Curr. Neurovasc. Res. 1, 3-10. doi: 10.2174/ 1567202043480242

Koyama, R., and Matsuki, N. (2010). Novel etiological and therapeutic strategies for neurodiseases: mechanisms and consequences of febrile seizures: lessons from animal models. J. Pharmacol. Sci. 113, 14-22. doi: 10.1254/jphs.09R19FM

Koyama, R., Tao, K., Sasaki, T., Ichikawa, J., Miyamoto, D., Muramatsu, R., et al. (2012). GABAergic excitation after febrile seizures induces ectopic granule cells and adult epilepsy. Nat. Med. 18, 1271-1278. doi: 10.1038/nm.2850

Lemmens, E. M., Lubbers, T., Schijns, O. E., Beuls, E. A., and Hoogland, G. (2005). Gender differences in febrile seizure-induced proliferation and survival in the rat dentate gyrus. Epilepsia 46, 1603-1612. doi: 10.1111/j.1528-1167.2005. 00252.x

Löscher, W., Klitgaard, H., Twyman, R. E., and Schmidt, D. (2013a). New avenues for anti-epileptic drug discovery and development. Nat. Rev. Drug Discov. 12, 757-776. doi: $10.1038 / \mathrm{nrd} 4126$

Löscher, W., Puskarjov, M., and Kaila, K. (2013b). Cation-chloride cotransporters NKCC1 and KCC2 as potential targets for novel antiepileptic and antiepileptogenic treatments. Neuropharmacology 69, 62-74. doi: 10.1016/j.neuropharm.2012.05.045

Mizrahi, E. M., and Watanabe, K. (2005). "Symptomatic neonatal seizures," in Epileptic Syndromes in Infancy, Childhood and Adolescence, eds J. Roger, M. Bureau, C. Dravet, P. Genton, C. A. Tassinari, and P. Wolf (Montrouge: John Libbey Eurotext Press), 17-38.

Norman, M. G. (1981). On the morphogenesis of ulegyria. Acta Neuropathol. 53, 331-332. doi: 10.1007/BF00690375

Painter, M. J., Scher, M. S., Stein, A. D., Armatti, S., Wang, Z., Gardiner, J. C., et al. (1999). Phenobarbital compared with phenytoin for the treatment of neonatal seizures. N. Engl. J. Med. 341, 485-489. doi: 10.1056/NEJM1999081234 1074

Peng, J., Li, R., Arora, N., Lau, M., Lim, S., Wu, C., et al. (2015). Effects of neonatal hypoxic-ischemic episodes on late seizure outcomes in C57 black mice. Epilepsy Res. 111, 142-149. doi: 10.1016/j.eplepsyres.2015.01.009

Pisani, F., Piccolo, B., Cantalupo, G., Copioli, C., Fusco, C., Pelosi, A., et al. (2012). Neonatal seizures and postneonatal epilepsy: a 7-y follow-up study. Pediatr. Res. 72, 186-193. doi: 10.1038/pr.2012.66

Pressler, R. M., Boylan, G. B., Marlow, N., Blennow, M., Chiron, C., Cross, J. H., et al. (2015). Bumetanide for the treatment of seizures in newborn babies with hypoxic ischaemic encephalopathy (NEMO): an open-label, dose finding, and feasibility phase 1/2 trial. Lancet Neurol. 14, 469-477. doi: 10.1016/S14744422(14)70303-5

Puskarjov, M., Kahle, K. T., Ruusuvuori, E., and Kaila, K. (2014). Pharmacotherapeutic targeting of cation-chloride cotransporters in neonatal seizures. Epilepsia 55, 806-818. doi: 10.1111/epi.12620

Rakhade, S. N., and Jensen, F. E. (2009). Epileptogenesis in the immature brain: emerging mechanisms. Nat. Rev. Neurol. 5, 380-391. doi: 10.1038/nrneurol. 2009.80

Rakhade, S. N., Klein, P. M., Huynh, T., Hilario-Gomez, C., Kosaras, B., Rotenberg, A., et al. (2011). Development of later life spontaneous seizures in a rodent model of hypoxia-induced neonatal seizures. Epilepsia 52, 753-765. doi: 10.1111/j.1528-1167.2011.02992.x

Rennie, J., and Boylan, G. (2007). Treatment of neonatal seizures. Arch. Dis. Child. Fetal Neonatal Ed. 92, F148-F150. doi: 10.1136/adc.2004.068551

Rice, J. E. III, Vannucci, R. C., and Brierley, J. B. (1981). The influence of immaturity on hypoxic-ischemic brain damage in the rat. Ann. Neurol. 9, 131-141. doi: 10.1002/ana.410090206
Ronen, G. M., Buckley, D., Penney, S., and Streiner, D. L. (2007). Longterm prognosis in children with neonatal seizures: a population-based study. Neurology 69, 1816-1822. doi: 10.1212/01.wnl.0000279335.85797.2c

Saliba, E. (2001). Perinatal brain injury. Semin. Neonatol. 6, 97-98. doi: 10.1053/ siny.2001.0040

Sampath, D., White, A. M., and Raol, Y. H. (2014). Characterization of neonatal seizures in an animal model of hypoxic-ischemic encephalopathy. Epilepsia 55, 985-993. doi: 10.1111/epi.12646

Schuchmann, S., Schmitz, D., Rivera, C., Vanhatalo, S., Salmen, B., Mackie, K., et al. (2006). Experimental febrile seizures are precipitated by a hyperthermiainduced respiratory alkalosis. Nat. Med. 12, 817-823. doi: 10.1038/nm1422

Slaughter, L. A., Patel, A. D., and Slaughter, J. L. (2013). Pharmacological treatment of neonatal seizures: a systematic review. J. Child Neurol. 28, 351-364. doi: $10.1177 / 0883073812470734$

Smith, A. L., Alexander, M., Rosenkrantz, T. S., Sadek, M. L., and Fitch, R. H. (2014a). Sex differences in behavioral outcome following neonatal hypoxia ischemia: insights from a clinical meta-analysis and a rodent model of induced hypoxic ischemic brain injury. Exp. Neurol. 254, 54-67. doi: 10.1016/j. expneurol.2014.01.003

Smith, A. L., Hill, C. A., Alexander, M., Szalkowski, C. E., Chrobak, J. J., Rosenkrantz, T. S., et al. (2014b). Spatial working memory deficits in male rats following neonatal hypoxic ischemic brain injury can be attenuated by task modifications. Brain Sci. 4, 240-272. doi: 10.3390/brainsci4020240

Stafstrom, C. E., Thompson, J. L., and Holmes, G. L. (1992). Kainic acid seizures in the developing brain: status epilepticus and spontaneous recurrent seizures. Brain Res. Dev. Brain Res. 65, 227-236. doi: 10.1016/0165-3806(92)90184-X

Stefovska, V. G., Uckermann, O., Czuczwar, M., Smitka, M., Czuczwar, P., Kis, J., et al. (2008). Sedative and anticonvulsant drugs suppress postnatal neurogenesis. Ann. Neurol. 64, 434-445. doi: 10.1002/ana.21463

Sun, H., Juul, H. M., and Jensen, F. E. (2016). Models of hypoxia and ischemiainduced seizures. J. Neurosci. Methods 260, 252-260. doi: 10.1016/j.jneumeth. 2015.09.023

Talos, D. M., Follett, P. L., Folkerth, R. D., Fishman, R. E., Trachtenberg, F. L., Volpe, J. J., et al. (2006). Developmental regulation of $\alpha$-amino-3hydroxy-5-methyl-4-isoxazole-propionic acid receptor subunit expression in forebrain and relationship to regional susceptibility to hypoxic/ischemic injury. II. Human cerebral white matter and cortex. J. Comp. Neurol. 497, 61-77. doi: $10.1002 /$ cne.20978

Tao, K., Ichikawa, J., Matsuki, N., Ikegaya, Y., and Koyama, R. (2016). Experimental febrile seizures induce age-dependent structural plasticity and improve memory in mice. Neuroscience 318, 34-44. doi: 10.1016/j.neuroscience.2016.01.011

Temkin, N. R. (2009). Preventing and treating posttraumatic seizures: the human experience. Epilepsia 50(Suppl. 2), 10-13. doi: 10.1111/j.1528-1167.2008. 02005.x

Theodore, W. H., Bhatia, S., Hatta, J., Fazilat, S., DeCarli, C., Bookheimer, S. Y., et al. (1999). Hippocampal atrophy, epilepsy duration, and febrile seizures in patients with partial seizures. Neurology 52, 132-136. doi: 10.1212/WNL. 52.1.132

Toth, Z., Yan, X. X., Haftoglou, S., Ribak, C. E., and Baram, T. Z. (1998). Seizureinduced neuronal injury: vulnerability to febrile seizures in an immature rat model. J. Neurosci. 18, 4285-4294. doi: 10.1523/JNEUROSCI.18-11-04285.1998

Ullal, G. R., Satishchandra, P., and Shankar, S. K. (1996). Hyperthermic seizures: an animal model for hot-water epilepsy. Seizure 5, 221-228. doi: 10.1016/S10591311(96)80040-9

van Gassen, K. L., Hessel, E. V., Ramakers, G. M., Notenboom, R. G., WolterinkDonselaar, I. G., Brakkee, J. H., et al. (2008). Characterization of febrile seizures and febrile seizure susceptibility in mouse inbred strains. Genes Brain Behav. 7, 578-586. doi: 10.1111/j.1601-183X.2008.00393.x

Verity, C. M., and Golding, J. (1991). Risk of epilepsy after febrile convulsions: a national cohort study. BMJ 303, 1373-1376. doi: 10.1136/bmj.303.6814.1373

Vestergaard, M., and Christensen, J. (2009). Register-based studies on febrile seizures in Denmark. Brain Dev. 31, 372-377. doi: 10.1016/j.braindev.2008. 11.012

Volpe, J. J. (2008). Neonatal encephalitis and white matter injury: more than just inflammation? Ann. Neurol. 64, 232-236. doi: 10.1002/ana.21466

Wang, S., Zhang, X. Q., Song, C. G., Xiao, T., Zhao, M., Zhu, G., et al. (2015). In vivo effects of bumetanide at brain concentrations incompatible with NKCC1 inhibition on newborn DGC structure and spontaneous EEG seizures following 
hypoxia-induced neonatal seizures. Neuroscience 286, 203-215. doi: 10.1016/j. neuroscience.2014.11.031

World Health Organization (2011). Guidelines on Neonatal Seizures. Geneva: World Health Organization.

Williams, P. A., Dou, P., and Dudek, F. E. (2004). Epilepsy and synaptic reorganization in a perinatal rat model of hypoxia-ischemia. Epilepsia 45, 1210-1218. doi: 10.1111/j.0013-9580.2004.60403.x

Williams, P. A., and Dudek, F. E. (2007). A chronic histopathological and electrophysiological analysis of a rodent hypoxic-ischemic brain injury model and its use as a model of epilepsy. Neuroscience 149, 943-961. doi: 10.1016/j. neuroscience.2007.07.067
Conflict of Interest Statement: The authors declare that the research was conducted in the absence of any commercial or financial relationships that could be construed as a potential conflict of interest.

Copyright ( 2018 Kasahara, Ikegaya and Koyama. This is an open-access article distributed under the terms of the Creative Commons Attribution License (CC BY). The use, distribution or reproduction in other forums is permitted, provided the original author(s) and the copyright owner are credited and that the original publication in this journal is cited, in accordance with accepted academic practice. No use, distribution or reproduction is permitted which does not comply with these terms. 